(C) <2018>. This manuscript version is made available under the CC-BY-NC-ND 4.0 license http://creativecommons.org/licenses/by-nc-nd/4.0/

The definitive publisher version is available online at 10.1016/j.energy.2018.07.039 


\section{Experimental study on combustion characteristics of}

\section{an n-butanol-biodiesel droplet}

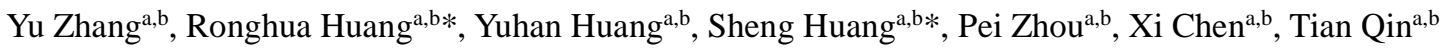

${ }^{a}$ State Key Laboratory of Coal Combustion, Huazhong University of Science and Technology, Wuhan, 430074, China

${ }^{b}$ School of Energy and Power Engineering, Huazhong University of Science and Technology, Wuhan, 430074, China

\section{$6 \quad$ Abstract} of BUT00 (pure biodiesel) and BUT50 (50\% n-butanol and 50\% biodiesel by mass) were investigated using droplet suspension technology under 1 bar and $900 \mathrm{~K}$. One flame is observed for BUT00 while two flames are observed for BUT50. The flame of BUT00 underwent successively faint luminosity, bright luminosity, soot aggregate and soot spread. The first flame of BUT50 was

11 faint and the second one was similar to that of BUT00 because they were caused by n-butanol and biodiesel combustion

12 respectively. Before the auto-ignition of BUT00, $\left(\mathrm{D} / \mathrm{D}_{0}\right)^{2}$ was approximately unchanged at 1.0 and similarity degree $(\mathrm{SD})$ was higher than 97\%. Temperature growth rate (TGR) decreased first quickly and then slowly. After the auto-ignition of BUT00, $\left(\mathrm{D} / \mathrm{D}_{0}\right)^{2}$ sharply decreased and SD was in the range of 90-97\%. The flame heating led to the increase of TGR. For BUT50, obvious

15 fluctuations were found in $\left(\mathrm{D} / \mathrm{D}_{0}\right)^{2}, \mathrm{SD}$ and TGD. The SD of BUT50 was generally lower than $97 \%$. The $\left(\mathrm{D} / \mathrm{D}_{0}\right)^{2}$ of $\mathrm{BUT} 50$

16 included transient heating, fluctuation evaporation and equilibrium evaporation phases. Some characteristic parameters were 17 deterministic although $\left(\mathrm{D} / \mathrm{D}_{0}\right)^{2}$ in fluctuation evaporation phase was a non-deterministic process.

18 Keywords: Combustion characteristics; Single droplet; n-Butanol; Biodiesel; Experimental study 
20 (1) One flame is observed for BUT00 while two flames are observed for BUT50.

21 (2) The first and second flames of BUT50 were caused by n-butanol and biodiesel combustion respectively.

22 (3) Similarity degree of BUT00 was higher than 97\% before auto-ignition and 90-97\% after auto-ignition.

23 (4) Similarity degree of BUT50 was generally lower than 97\%.

24 (5) Obvious fluctuations were found in $\left(\mathrm{D} / \mathrm{D}_{0}\right)^{2}$, similarity degree and temperature growth rate for BUT50.

\section{Nomenclature}

\begin{tabular}{|llll|}
\hline C & Rate constant, $\left[\mathrm{mm}^{2} / \mathrm{s}\right]$ & end & End point of fluctuation evaporation phase \\
$\mathrm{D}$ & Droplet diameter, $[\mathrm{mm}]$ & $\max$ & Maximum \\
$\mathrm{I}$ & Light intensity, $[-]$ & sta & Start point of fluctuation evaporation phase \\
$\mathrm{i}$ & Horizontal coordinate, $[-]$ & total & Total lifetime \\
$\mathrm{j}$ & Vertical coordinate, $[-]$ & Abbreviation & \\
$\mathrm{P}$ & Image in the region of interest, $[-]$ & ARC & Average rate constant \\
$\mathrm{T}$ & Droplet temperature, $[\mathrm{K}]$ & BUT00 & Pure biodiesel \\
$\mathrm{t}$ & Time, $[\mathrm{s}]$ & $\mathrm{BUT} 50$ & Blend of $50 \%$ n-butanol and $50 \%$ biodiesel \\
$\Delta \mathrm{t}$ & Interval time, $\left[\mathrm{s} / \mathrm{mm}^{2}\right]$ & $\mathrm{CT}$ & Characteristic time \\
$\tau$ & Duration, $\left[\mathrm{s} / \mathrm{mm}^{2}\right]$ & $\mathrm{EE}$ & Equilibrium evaporation phase \\
$\mathrm{Subscripts}$ & & FE & Fluctuation evaporation phase \\
0 & Initial condition & PCP & Puffing characteristic parameter \\
1 & First & SD & Similarity degree \\
2 & Second & TH & Transient heating phase \\
amb & Ambient environment & TGR & Temperature growth rate \\
dro & Droplet & & \\
\hline
\end{tabular}

\section{Introduction} and environmental protection make it essential to find environmentally friendly and renewable fuels. Biodiesel and alcohols are two promising renewable fuels for transportation. Table 1 shows physical properties of biodiesel, diesel, n-butanol and n-ethanol. n-Butanol is more competitive than n-ethanol due to the following two reasons. Firstly, the production of n-ethanol decreases the 

because it has greater miscibility with diesel, higher calorific value $\left(3.31 \times 10^{7} \mathrm{~J} / \mathrm{kg}\right)$ and larger cetane number (25) than ethanol

35

(calorific value $=2.68 \times 10^{7} \mathrm{~J} / \mathrm{kg}$, cetane number $=8$ ) $[4,5]$. However, $\mathrm{n}$-butanol cannot be used in diesel engines alone because of its lower kinematic viscosity $\left(2.22 \times 10^{-6} \mathrm{~m}^{2} / \mathrm{s}\right)$, calorific value and cetane number than those of diesel (kinematic viscosity $=2.42 \times 10^{-6}$ $\mathrm{m}^{2} / \mathrm{s}$, calorific value $=4.25 \times 10^{7} \mathrm{~J} / \mathrm{kg}$, cetane number $=47.1$ ) [6]. Biodiesel is also applied in diesel engines because its physical properties are similar with those of diesel. Biodiesel can be produced from many sources, including vegetable oils, animal fats, algae, etc $[7,8]$. The use of biodiesel leads to the substantial decrease in particulate matter (PM), hydrocarbon (HC) and carbon monoxide $(\mathrm{CO})$ emissions $[7,9]$. However, the addition of biodiesel can lead to higher nitrogen oxides $\left(\mathrm{NO}_{\mathrm{x}}\right)$ emissions and fuel consumption than pure diesel does $[9,10]$. High kinematic viscosity $\left(4.0 \times 10^{-6} \mathrm{~m}^{2} / \mathrm{s}\right)$ and boiling point $(615 \mathrm{~K})$ of biodiesel lead to poor atomization, evaporation and combustion processes [11].

Table 1 Physical properties of biodiesel, diesel, n-butanol and n-ethanol [12, 13]

\begin{tabular}{|c|c|c|c|c|}
\hline Physical properties & Biodiesel (ASTM) & Diesel (ASTM, D975) & n-Butanol & n-Ethanol \\
\hline Molecular formula & $\mathrm{C}_{12}-\mathrm{C}_{24}$ & $\mathrm{C}_{12}-\mathrm{C}_{25}$ & $\mathrm{C}_{4} \mathrm{H}_{9} \mathrm{OH}$ & $\mathrm{C}_{2} \mathrm{H}_{5} \mathrm{OH}$ \\
\hline Lower calorific value, $[\mathrm{J} / \mathrm{kg}]$ & $3.75 \times 10^{7}(\mathrm{D} 240)$ & $4.25 \times 10^{7}$ & $3.31 \times 10^{7}$ & $2.68 \times 10^{7}$ \\
\hline Latent heat at $298 \mathrm{~K},[\mathrm{~J} / \mathrm{kg}]$ & $2.00 \times 10^{5}$ & $2.50 \times 10^{5}$ & $5.82 \times 10^{5}$ & $9.04 \times 10^{5}$ \\
\hline Cetane number, $[-]$ & $51(\mathrm{D} 613)$ & 47.1 & 25 & 8 \\
\hline Kinematic viscosity at $313 \mathrm{~K},\left[\mathrm{~m}^{2} / \mathrm{s}\right]$ & $4.0 \times 10^{-6}(\mathrm{D} 445)$ & $2.42 \times 10^{-6}$ & $2.22 \times 10^{-6}$ & $1.08 \times 10^{-6}$ \\
\hline Oxygen content, [\%] & 10 & - & 21.6 & 34.8 \\
\hline Density at $293 \mathrm{~K},\left[\mathrm{~kg} / \mathrm{m}^{3}\right]$ & 887 at $288 \mathrm{~K}$ (D1298) & 837 & 810 & 790 \\
\hline Boiling point at $1 \mathrm{bar},[\mathrm{K}]$ & $615(\mathrm{D} 1160)$ & $453-643$ & 390.4 & 351.4 \\
\hline Auto-ignition temperature at $1 \mathrm{bar},[\mathrm{K}]$ & 636 & $\sim 483$ & 658 & 707 \\
\hline Flash point at closed cup, $[\mathrm{K}]$ & 447 (D93) & $338-361$ & 308 & 281 \\
\hline Surface tension at $293 \mathrm{~K},[\mathrm{~N} / \mathrm{m}]$ & 34.4 & 31.4 & 24.6 & 22.3 \\
\hline
\end{tabular}

Blending biodiesel with n-butanol has the potential of offsetting their respective disadvantages [14, 15]. Zheng et al. [16, 17] researched performance and emission characteristics of n-butanol-biodiesel blends on a single-cylinder diesel engine. The optimum combustion and emissions performance could be achieved using BUT50 and high exhaust gas recirculation (EGR) rate. Therefore, BUT50 is an attractive fuel for diesel engines and is selected as the test fuel in this work. The spray process largely determines the combustion and emissions performance of diesel engines. Li et al. [18] and Mo et al. [19] researched macroscopic spray characteristics of n-butanol-biodiesel blends. With the increase of n-butanol content, spray tip penetration decreased while spray area and cone angle increased. The addition of n-butanol to biodiesel could improve engine performance in four ways. 
Firstly, the atomization was improved because the kinematic viscosity $\left(2.22 \times 10^{-6} \mathrm{~m}^{2} / \mathrm{s}\right)$ and surface tension $(24.6 \mathrm{~N} / \mathrm{m})$ of

n-butanol were lower than those of biodiesel (kinematic viscosity $=4.0 \times 10^{-6} \mathrm{~m}^{2} / \mathrm{s}$ and surface tension $=34.4 \mathrm{~N} / \mathrm{m}$ ) $[18,19]$. Secondly, the obvious difference of boiling points between n-butanol (390.4 K) and biodiesel (615 K) led to puffing and micro-explosion processes, which further improved the atomization process [20]. Thirdly, soot emissions could be further decreased because the oxygen content of n-butanol (21.6\%) was higher than that of biodiesel (10\%) [12, 17]. Fourthly, the long auto-ignition delay led to improved fuel-air mixing and increased proportion of premixed combustion because the cetane number of n-butanol (25) was lower than that of biodiesel (51) [16, 17].

It is meaningful to research combustion characteristics of single droplet because it contains similar physical and chemical processes with spray [21]. Droplet combustion is studied by freely falling and droplet suspension technologies. The advantage of freely falling technology is to eliminate the influence of suspension wire. However, auto-ignition characteristics are not researched by the freely falling technology because the droplet is ignited by a flat-flame burner [22, 23]. Although the droplet suspension technology has the disadvantages of heterogeneous bubble nucleation [24] and enhanced heat conduction through the thermocouple [25], it is still widely used because of its synchronous measurement of droplet temperature and images [24, 26, 27]. Some works have been conducted to research droplet combustion of pure n-butanol [28, 29], pure biodiesel [30, 31] and diesel-biodiesel-alcohol (methanol, ethanol and propanol) blends [22, 32, 33]. However, only few works were reported on droplet combustion of n-butanol-biodiesel blends. Hoxie et al. [34] researched micro-explosion and combustion characteristics of n-butanol-soybean oil blends. Their results showed that the frequency and intensity of micro-explosion were the highest for BUT40 (the blend of 40\% n-butanol and 60\% soybean oil by volume). BUT75 displayed three-stage burning behavior, including the steady burning of n-butanol, flame shrinkage of n-butanol and the steady burning of soybean oil. Similar results were also reported in Ref. [22] using ethanol-diesel-biodiesel blends. Coughlin et al. [35] researched combustion characteristics of pentanol-butanol-vegetable oil blends. They found that equi-volume blend of pentanol, butanol and soybean oil exhibited the most violent micro-explosion and the shortest reaction time. However, auto-ignition characteristics were not studied because the droplet was ignited by an igniter [34, 35]. Zhang et al. [36] researched puffing characteristics of n-butanol-biodiesel blends at the ambient temperature of $1073 \mathrm{~K}$. The results showed that BUT25 (the blend of 25\% n-butanol and $75 \%$ biodiesel by mass) only 
demonstrated core puffing mode while BUT75 demonstrated surface and core puffing modes simultaneously. However, only puffing characteristics were emphatically analyzed and combustion characteristics were rarely discussed in Ref. [36].

As reviewed above, few works have been reported on droplet combustion of n-butanol-biodiesel blends although it is of great importance to understand the fundamentals of spray combustion. Therefore, this work was aimed to investigate auto-ignition and combustion characteristics of an n-butanol-biodiesel droplet. The droplet suspension technology was used under $900 \mathrm{~K}$ and 1 bar. Thermocouples were used to measure droplet and gas temperatures. Droplet and flame images were record by a high-speed camera. The temperature growth rate and similarity degree were proposed to study transient changes of droplet temperature and shape.

\section{Experimental apparatus and methods}

Fig. 1 displays a schematic diagram and a photograph of experimental apparatus. The apparatus consists of a heating system, a droplet generation and transport system and a data acquisition system. The heating system contains a heating chamber, six heating rods and a temperature controller. The heating chamber has an inner structure of cylinder with a diameter of $100 \mathrm{~mm}$ and a height of $100 \mathrm{~mm}$. The heating chamber is wrapped by a layer of quartz wool for insulation. The six heating rods are the heating source in the heating chamber. Two quartz glasses are installed in the front and rear of the heating chamber. The two quartz glasses have a diameter of $60 \mathrm{~mm}$ and a thickness of $15 \mathrm{~mm}$.

As shown in Fig. 1, the droplet generation and transport system includes a droplet generation part, a droplet transport part and a thermal insulation part, which are driven by three step motors. The three motors are connected to a stepper motor controller. The direction and distance of movement are precisely controlled by the stepper motor controller. The droplet generation part contains a stepper motor of $2 \#$, a microliter syringe, a copper wire and a thermocouple of bare wire. The linear movement of microliter syringe is driven by the stepper motor of $2 \#$. The copper wire is inserted into the syringe needle. The diameters of the syringe needle, copper wire and thermocouple wire are $0.50,0.10$ and $0.127 \mathrm{~mm}$, respectively. The droplet transport part includes an alundum tube, a supporting seat, a cantilever, a sliding block, a guide rail and a stepper motor of 1 \#. The thermocouple of bare wire is placed in the alundum tube to protect the thermocouple from high temperature environment. The alundum tube is fixed in the cantilever through the supporting seat. The cantilever is connected to the sliding block on the guide rail. The sliding block is 
a stepper motor of $3 \#$. The thermal baffle is driven by the stepper motor of $3 \#$.

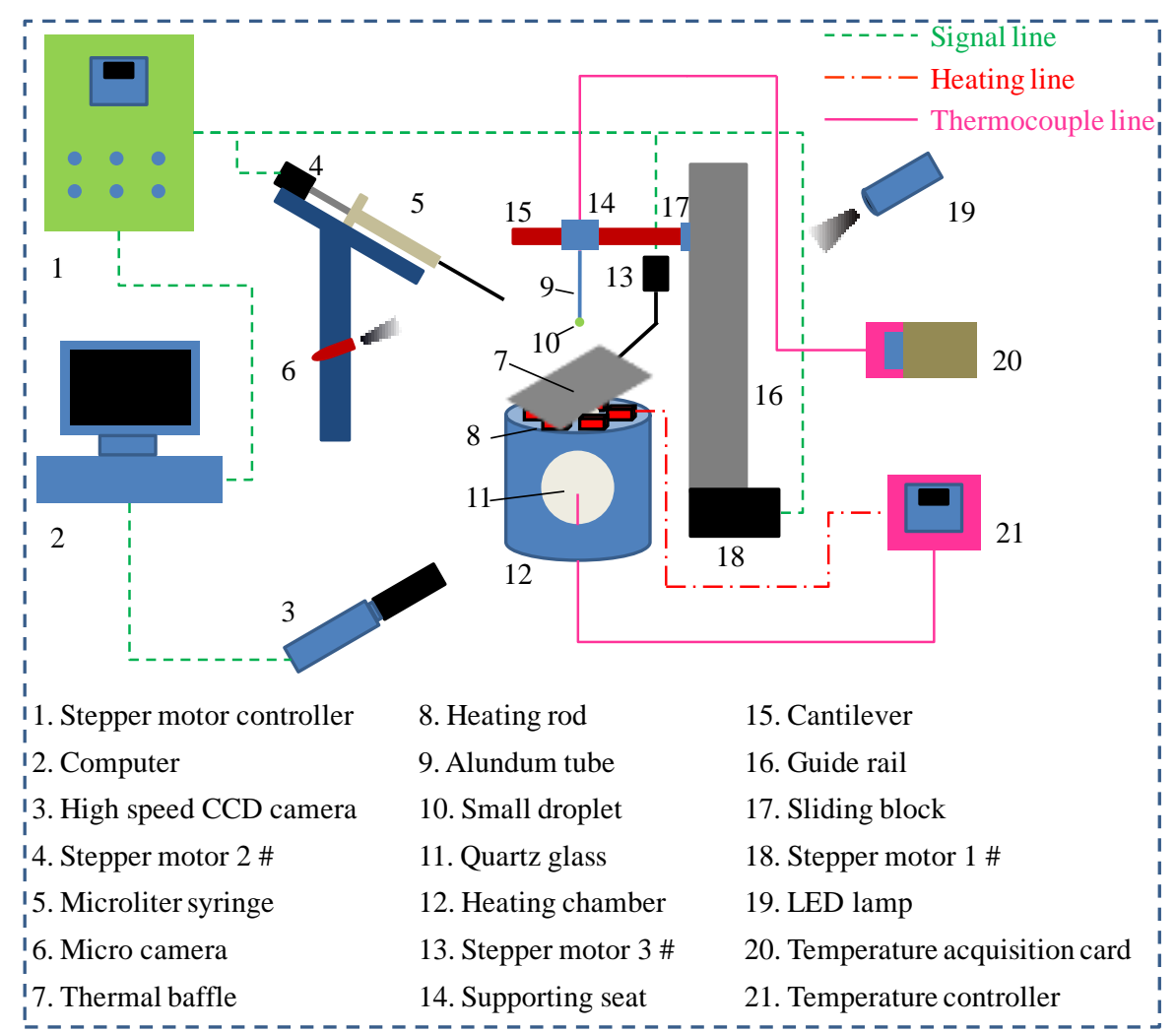

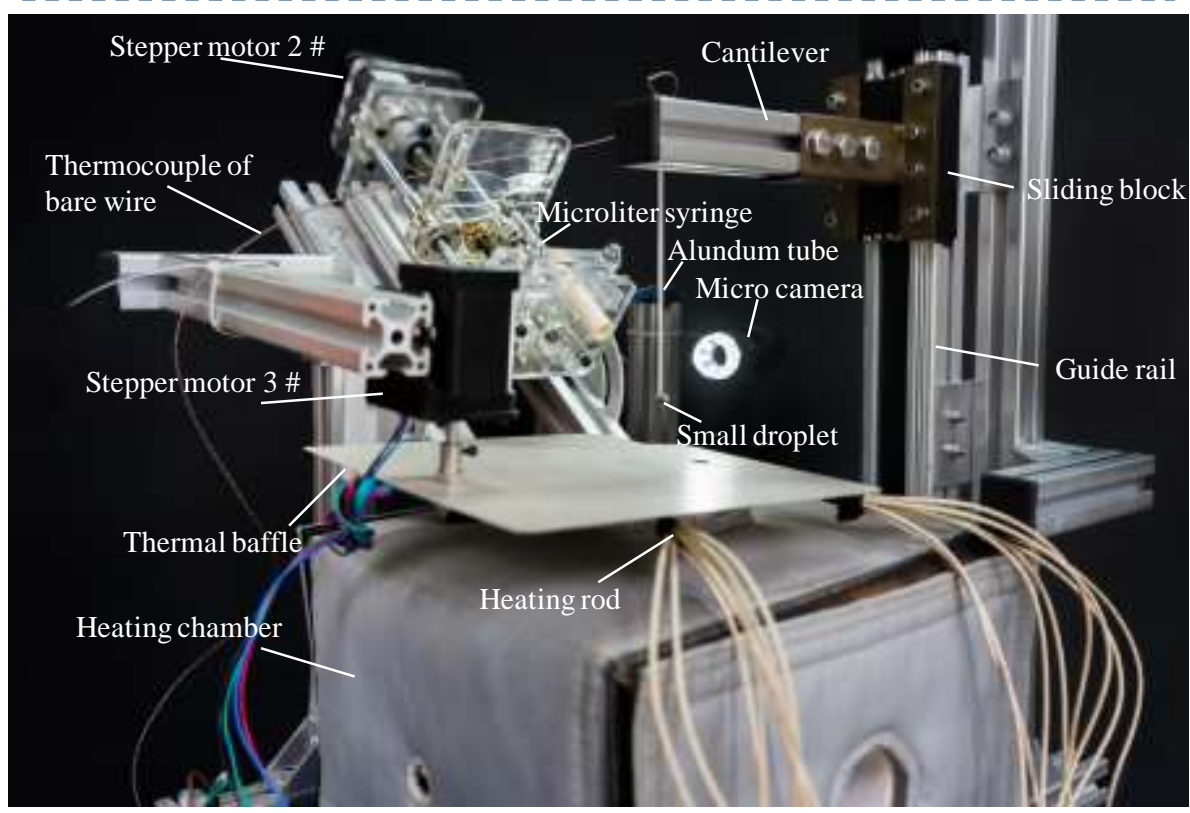

Fig. 1. Schematic diagram and photograph of experimental apparatus.

Fig. 2 shows a working process of the droplet generation and transport system. The working process can be divided into six steps. Firstly, the microliter syringe moves right and the syringe needle approaches the thermocouple of bare wire. When the bulge of syringe tube contacts with the baffle, the syringe needle must contact with the thermocouple of bare wire. At the same time, a droplet adheres to the needle surface. Secondly, the microliter syringe moves left and the droplet adheres to the junction between 
the thermocouple wire and needle. With the left movement of syringe, the droplet adheres to the junction between the

thermocouple wire and copper wire. The copper wire is a transition between the syringe needle and thermocouple wire. When the

copper wire is separated from the thermocouple wire, the droplet will be suspended on the junction of thermocouple. Thirdly, the

left movement of thermal baffle makes the channel of droplet transport open. Fourthly, the droplet is still on the thermocouple

111 junction and transported into the heating chamber. It is defined as the initial time when the droplet arrives at the final location [27].

112 Initial condition includes initial droplet diameter and temperature. Average initial diameter and temperature are $1.24 \mathrm{~mm}$ and

$113 \quad 349.2 \mathrm{~K}$, whose relative uncertainties are $0.87 \%$ and $1.52 \%$ respectively. Fifthly, the thermocouple of bare wire is withdrawn from

114 the heating chamber when the droplet evaporation is finished. Finally, the thermal baffle moves right and returns to the initial

location. The purpose of thermal baffle is to decrease the heating of high temperature gas due to the buoyancy effect.

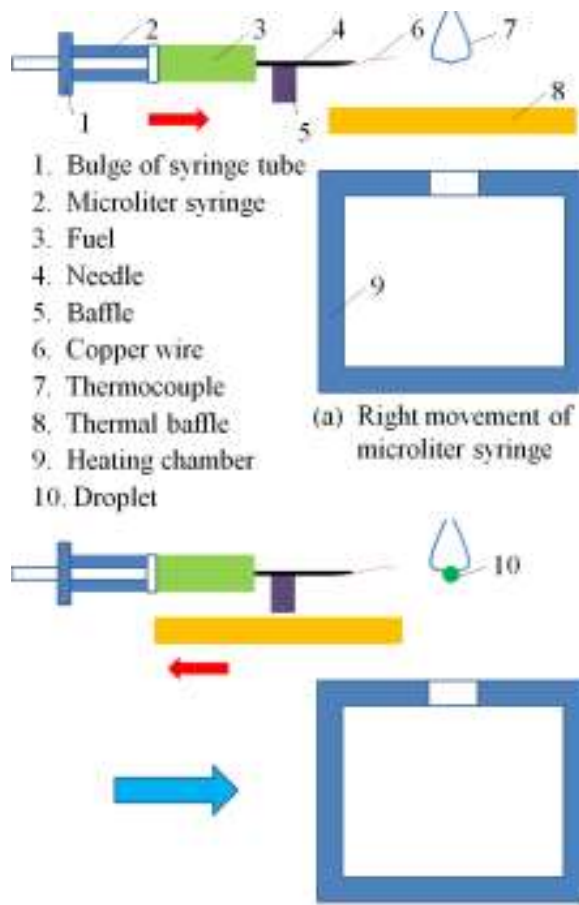

(c) Left movement of thermal baffle

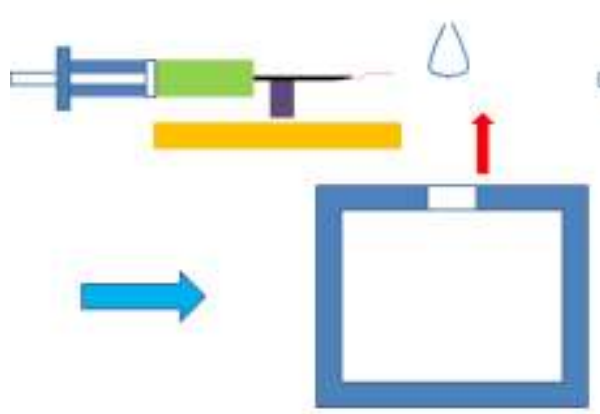

(e) Up movement of thermocouple
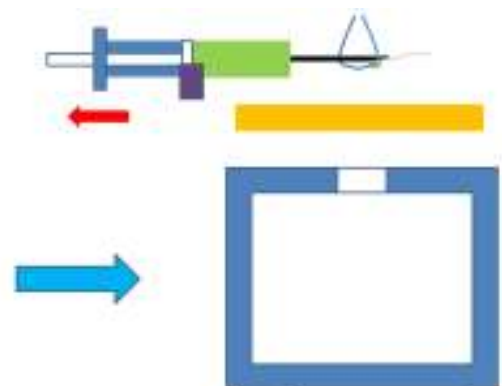

(b) Left movement of microliter syringe

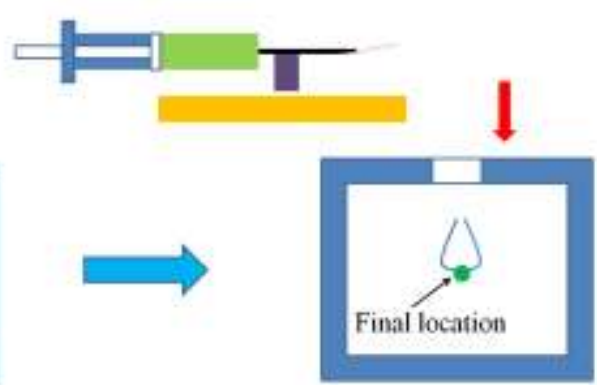

(d) Down movement of thermocouple

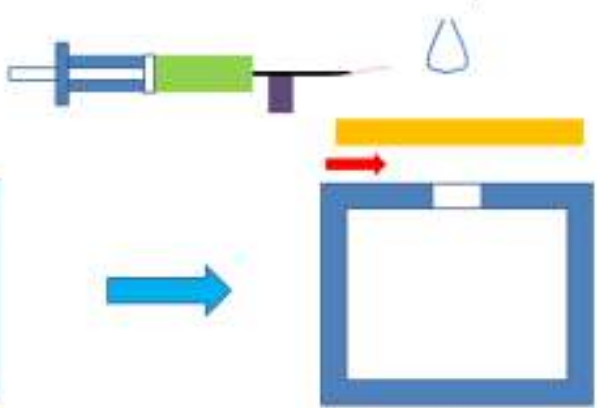

(f) Right movement of thermal bafle

Fig. 2. Working process of droplet generation and transport system. 
Micro-ED 200mm f/4), whose aperture is set as $32 \mathrm{~mm}$, is placed in the front of the camera. The sampling frequency of

temperature acquisition card is $100 \mathrm{~Hz}$. Fig. 3 shows a schematic diagram of image processing program, which is developed using

$(300 \times 300$ pixels) is abstracted from the original image to analyze the droplet change. To extract the boundary, a binarization

process is carried out based on Eq. (1),

$$
I=\left(2 I_{d r o}+I_{a m b}\right) / 3
$$

where $I_{d r o}$ and $I_{a m b}$ are light intensities of the droplet and ambient environment [37]. The pixel number of droplet is calculated by

eliminating the image of thermocouple. The droplet size is calculated based on the pixel number of droplet and the spatial

resolution of 76 pixels $/ \mathrm{mm}$. The square of droplet diameter and time are normalized by the square of initial droplet diameter

because droplet sizes are not identical in repeated experiments. The similarity degree (SD) is calculated using Eq. (2),

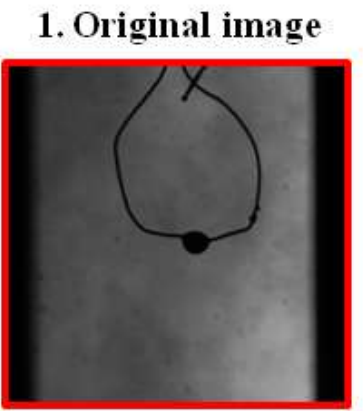

$1024 \times 1024$ pixels

\section{Similarity degree}

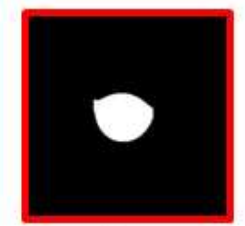

$P_{1}$

\section{Region of interest 3. Binarization}

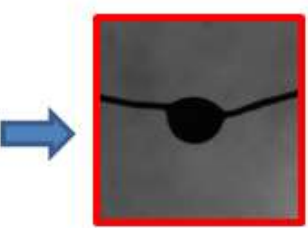

$300 \times 300$ pixels

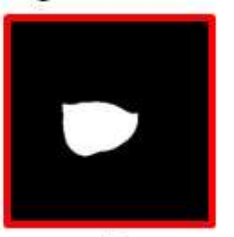

$\mathrm{P}_{2}$
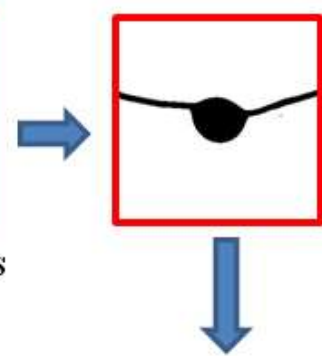

4. Cut thermocouple

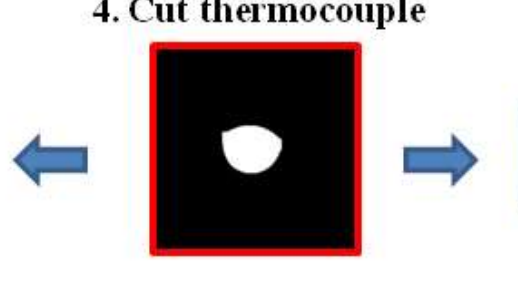

\section{Rate constant}

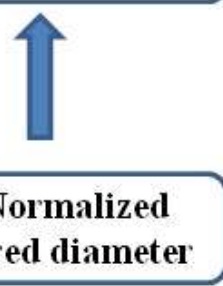

\section{Normalized squared diameter}

Two consecutive images

Fig. 3. Schematic diagram of image processing program.

$$
S D=100 \%-\sqrt{\frac{\sum_{i, j}^{300 \times 300}\left(P_{1}(i, j)-P_{2}(i, j)\right)^{2}}{300 \times 300}}
$$

where $P$ represents the image in the region of interest, $P_{1}$ and $P_{2}$ denote the first and second images of two consecutive images. 
whose horizontal and vertical coordinates are $i$ and $j$. After binarization, the value of $P(i, j)$ is 0 or 1 . The presence of $300 \times 300$ in

the denominator of Eq. (2) corresponds to the spatial resolution in the region of interest. SD reflects transient variation of droplet

shape. A low SD indicates obvious droplet change between two consecutive images. The temperature growth rate (TGR) is

defined by Eq. (3),

$$
T G R=\frac{T_{2}-T_{1}}{\Delta t}
$$

where $T_{1}$ and $T_{2}$ are the first and second temperatures of two consecutive droplet temperatures, $\Delta t$ is the normalized interval time

of temperature data. More details on the experimental apparatus and image processing program can be found in Refs. [6, 36, 38].

was the blend of 50\% n-butanol (99.7\% purity) and 50\% biodiesel by mass. The experiments were conducted under the ambient

pressure of 1 bar and ambient temperature of $900 \mathrm{~K}$.

\section{Results and discussion}

Fig. 4 shows evaporation and combustion processes of BUT00 and BUT50. In Fig. 4 (a), two lower thermocouples are placed

$8 \mathrm{~mm}$ below the droplet. The lower thermocouples of $1 \#$ and $2 \#$ are connected to the temperature acquisition card and temperature controller, respectively. The enlarged image of droplet is placed in the top left corner. For BUT00, the droplet goes through evaporation, auto-ignition, faint luminosity, bright luminosity, soot aggregate and soot spread. From 0.000 to $0.389 \mathrm{~s} / \mathrm{mm}^{2}$, stable evaporation is found and the droplet size is approximately unchanged. $0.389 \mathrm{~s} / \mathrm{mm}^{2}$ is defined as the auto-ignition time because faint luminosity is observed through comparing the red box in two consecutive images [39]. The auto-ignition location is found below the droplet. The fuel vapor tends to penetrate downward because the molecular weight of fuel vapor is heavier than auto-ignition delay, including a physical delay and a chemical delay, is a result of pre-combustion reactions in the fuel-air mixture [39]. The flame is getting gradually brighter from 0.389 to $0.420 \mathrm{~s} / \mathrm{mm}^{2}$. The bright flame is caused by soot incandescence [41]. 
Before $0.389 \mathrm{~s} / \mathrm{mm}^{2}$, the droplet is suspended on the thermocouple wire and junction. After $0.537 \mathrm{~s} / \mathrm{mm}^{2}$, the droplet is only

$0.611 \mathrm{~s} / \mathrm{mm}^{2}$ ) due to the vapor ejection of light components in biodiesel.

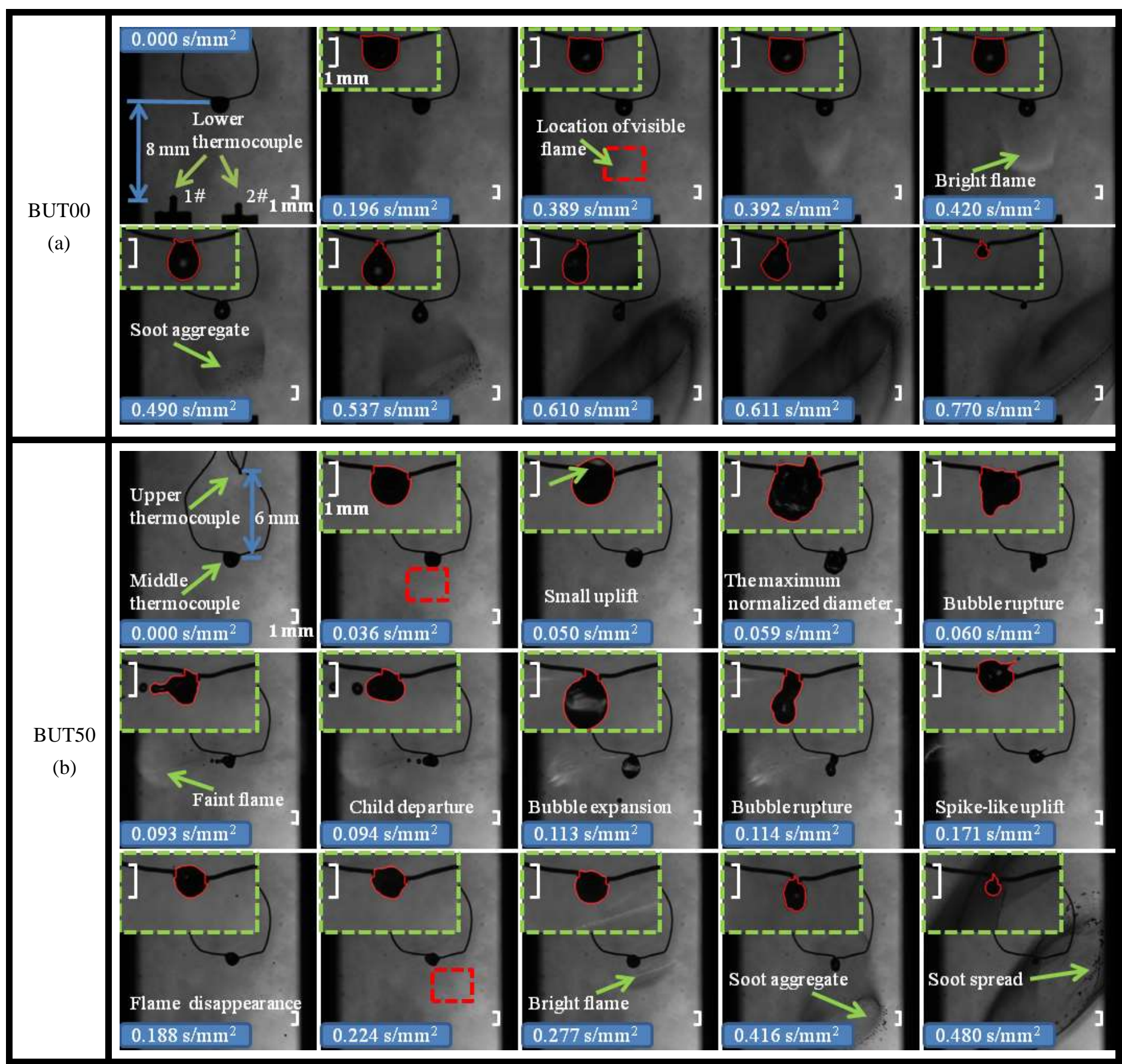

Fig. 4. Evaporation and combustion processes of BUT00 and BUT50.

In Fig. 4 (b), upper and middle thermocouples are also connected to the temperature acquisition card. The upper 
droplet. The first flame is from 0.036 to $0.188 \mathrm{~s} / \mathrm{mm}^{2}$. At $0.036 \mathrm{~s} / \mathrm{mm}^{2}$, the auto-ignition takes place because a slight change of

brightness can be observed in the red box. In the period of the first flame, the flame is faint and soot aggregate is not observed

because the first flame is caused by n-butanol combustion. The high oxygen content of n-butanol can promote soot oxidation and

decrease soot formation. Furthermore, obvious puffing process can be found in the period of the first flame. A small uplift is firstly

formed in the upper edge of droplet at $0.050 \mathrm{~s} / \mathrm{mm}^{2}$. The puffing process includes bubble expansion and rupture, which are

observed at 0.059 and $0.060 \mathrm{~s} / \mathrm{mm}^{2}$. After bubble rupture, two child droplets are continuously formed at 0.093 and $0.094 \mathrm{~s} / \mathrm{mm}^{2}$

due to violent droplet deformation. Because of the ejection of n-butanol vapor, a spike-like uplift is found on the droplet surface at

$0.171 \mathrm{~s} / \mathrm{mm}^{2}$. The second flame is from 0.224 to $0.480 \mathrm{~s} / \mathrm{mm}^{2}$. The droplet undergoes stable evaporation from the end of the first

flame to the beginning of the second flame. Similar to the flame of BUT00, the second flame of BUT50 also goes through faint

luminosity, bright luminosity, soot aggregate and soot spread. In the period of the second flame, no obvious bubble can be

observed inside the droplet. This indicates that a large amount of n-butanol has left the droplet and the second flame is caused by

biodiesel combustion. The continuous deformation of the spindly droplet can be also observed in the period of the second flame

(such as $0.416 \mathrm{~s} / \mathrm{mm}^{2}$ ). Fig. 5 shows temperature traces of the upper thermocouple. For BUT00, an obvious temperature increase

can be found after the auto-ignition because the flame increases the gas temperature around the droplet. For BUT50, a

flame formation and spread and the declining stage corresponds to flame shrinkage and extinction.

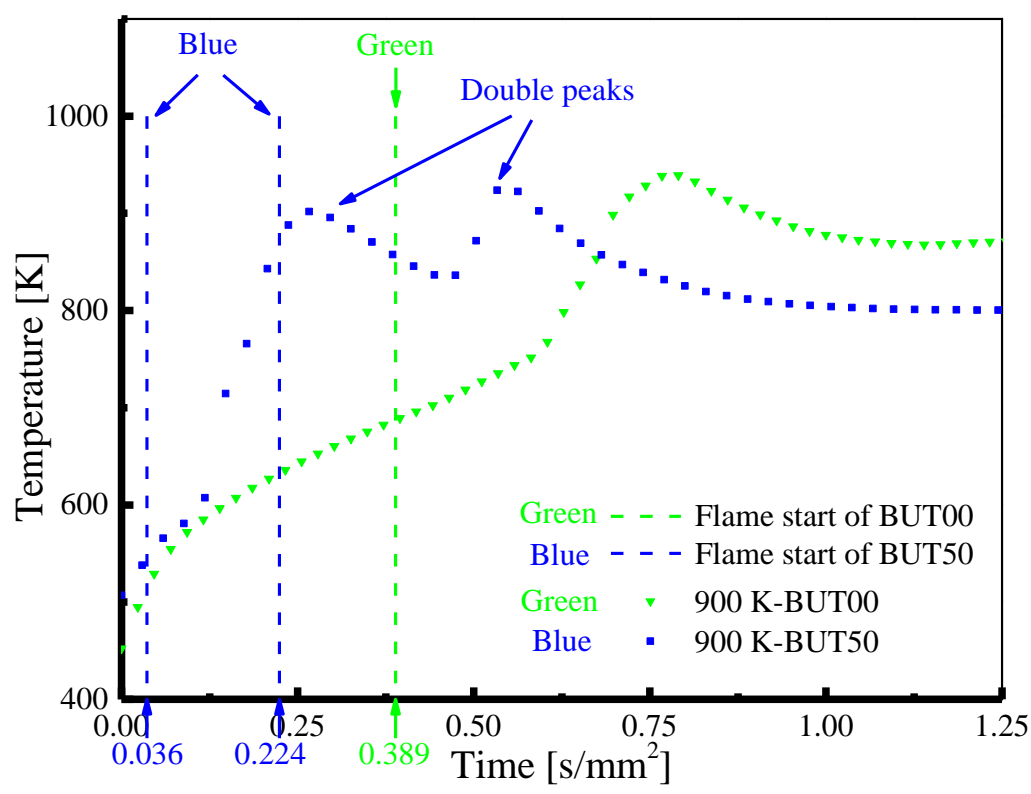

Fig. 5. Temperature traces of the upper thermocouple for BUT00 and BUT50. 
Fig. 6 illustrates normalized squared diameter $\left(\left(\mathrm{D} / \mathrm{D}_{0}\right)^{2}\right)$ and similarity degree $(\mathrm{SD})$ of BUT00 and BUT50. For BUT00 in Fig.

$6(a),\left(D / D_{0}\right)^{2}$ is almost unchanged at 1.0 and most of SD is in the range of $97-100 \%$ before the auto-ignition. From Fig. 4 (a), the droplet goes through stable evaporation before the auto-ignition. After the auto-ignition, $\left(\mathrm{D} / \mathrm{D}_{0}\right)^{2}$ drastically decreases and SD drops to the range of $90-97 \%$. The sharp decrease of $\left(D / D_{0}\right)^{2}$ is caused by the flame heating. The SD of $90-97 \%$ is caused by the continuous deformation of spindly droplet (such as 0.610 and $0.611 \mathrm{~s} / \mathrm{mm}^{2}$ in Fig. 4 (a)). Different from that of BUT00, the $\left(\mathrm{D} / \mathrm{D}_{0}\right)^{2}$ of BUT50 includes transient heating $(\mathrm{TH})$, fluctuation evaporation (FE) and equilibrium evaporation (EE) phases in Fig. 6 (b). Both TH and EE are stable evaporation processes. The $\left(\mathrm{D} / \mathrm{D}_{0}\right)^{2}$ and $\mathrm{SD}$ in FE exhibit high-frequency fluctuations because bubbles expand and break up repeatedly $[36,46]$. The three phases are distinguished by SD [36]. The dividing point between TH and FE $\left(0.050 \mathrm{~s} / \mathrm{mm}^{2}\right)$ is the time when SD drastically decreases. The dividing point between FE and EE $\left(0.261 \mathrm{~s} / \mathrm{mm}^{2}\right)$ is the time when the majority of SD enters the range of $90-100 \%$. The SD of BUT50 is generally lower than $97 \%$ because of two reasons. Firstly, a large amount of n-butanol is contained inside the droplet when the droplet is quickly heated by the first flame. This leads to obvious fluctuation of SD in the period of the first flame. Secondly, the continuous deformation of spindly droplet $\left(0.416 \mathrm{~s} / \mathrm{mm}^{2}\right.$ in Fig. 4 (b)) leads to the SD of 90-97\% in the period of the second flame.

As shown in Fig. 6 (b), the evolution of $\left(\mathrm{D} / \mathrm{D}_{0}\right)^{2}$ in $\mathrm{FE}$ is a non-deterministic process because of random bubble expansion and rupture. However, some characteristic parameters are deterministic, including puffing characteristic parameter (PCP), average rate constant (ARC) and characteristic time (CT). PCP includes $\tau_{\mathrm{TH}} / \tau_{\mathrm{total}}, \tau_{\mathrm{FE}} / \tau_{\text {total }}, \mathrm{t}_{\max } / \tau_{\text {total }}$ and $\left(\mathrm{D}_{\max } / \mathrm{D}_{0}\right)^{2}$, where $\tau_{\mathrm{TH}}$ and $\tau_{\mathrm{FE}}$ are the durations of TH and FE, $\left(\mathrm{D}_{\max } / \mathrm{D}_{0}\right)^{2}$ is the maximum value of $\left(\mathrm{D} / \mathrm{D}_{0}\right)^{2}$, and $\tau_{\text {total }}$ and $\mathrm{t}_{\max }$ are the droplet lifetime and the time of $\left(D_{\max } / \mathrm{D}_{0}\right)^{2}$. PCP is used to characterize the puffing process. ARC is important because it controls the combustion process. Based on $\mathrm{D}^{2}$ law, ARC of BUT00 can be calculated using a method of polynomial fitting through three steps $[42,43]$. Firstly, a fourth order polynomial fitting is applied to the curve of $\left(\mathrm{D} / \mathrm{D}_{0}\right)^{2}$ (see Fig. 6 (a)). Secondly, instantaneous rate constant is obtained through taking the derivative of polynomial fitting curve. Thirdly, ARC is calculated by averaging the instantaneous rate constant. CT includes droplet lifetime and auto-ignition delay, which have been described by red and pink vertical lines in Fig. 6. The reciprocal of droplet lifetime reflects the ARC in the total lifetime. The auto-ignition delay needs to be deeply studied because it has an important influence on engine performance and emission characteristics [44, 45]. 
Fig. 7 shows PCP of BUT50. $\tau_{\mathrm{TH}} / \tau_{\text {total }}, \tau_{\mathrm{FE}} / \tau_{\text {total }}, \mathrm{t}_{\max } / \tau_{\text {total }}$ and $\left(\mathrm{D}_{\max } / \mathrm{D}_{0}\right)^{2}$ are $7.26 \%, 43.43 \%, 11.84 \%$ and 2.05 and their

relative uncertainties are $15.56 \%, 8.38 \%, 8.11 \%$ and $5.37 \% . \tau_{\mathrm{TH}}$ and $\mathrm{t}_{\max }$ are determined by droplet temperature because the

droplet temperature at the end of $\mathrm{TH}$ is slightly lower and the droplet temperature at $\mathrm{t}_{\max }$ is slightly higher than the boiling point of
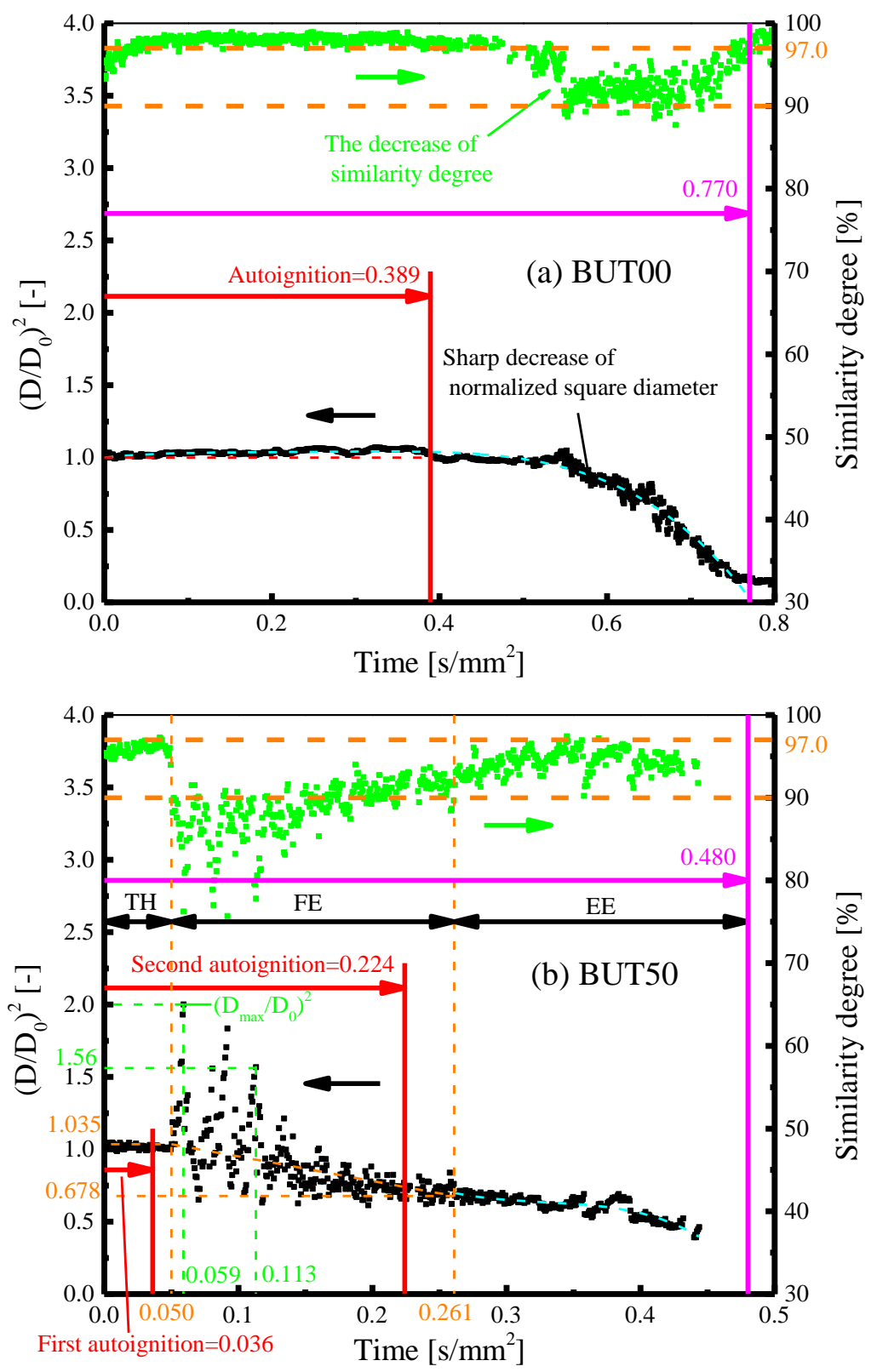

Fig. 6. Normalized squared diameter and similarity degree of BUT00 and BUT50. 


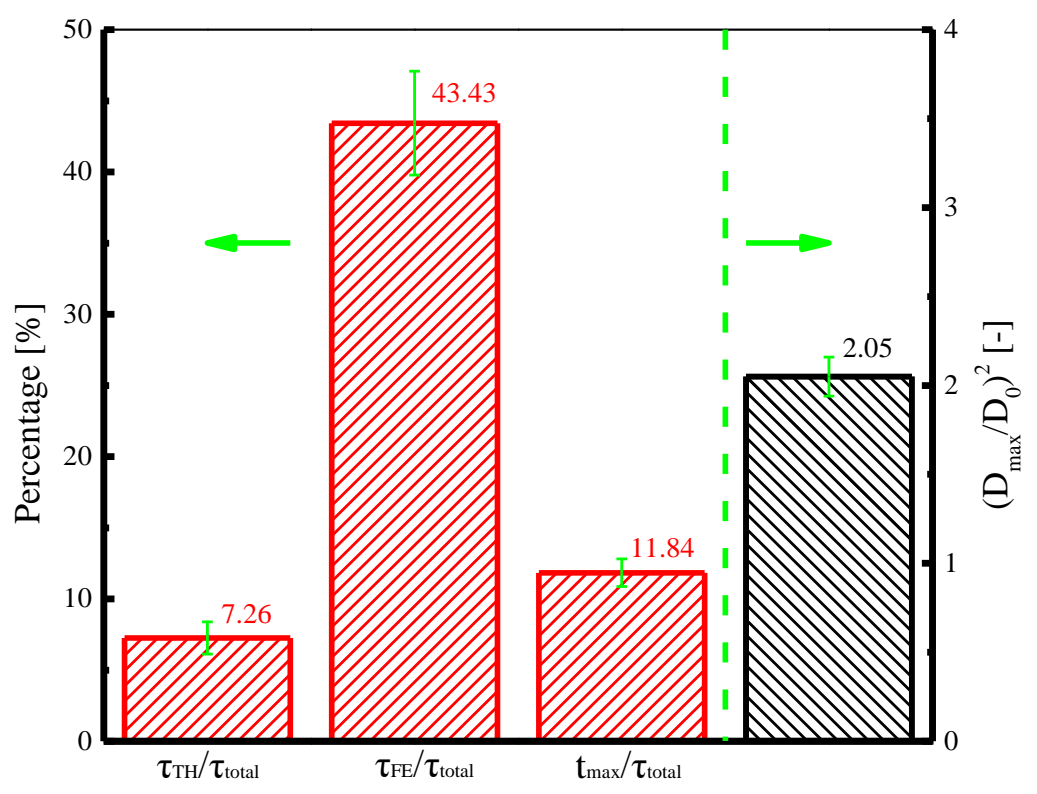

Fig. 7. Puffing characteristic parameter (PCP) of BUT50.

Fig. 8 shows ARC of BUT00 and BUT50. The calculation of ARC is separated by the auto-ignition because the curve of $\left(\mathrm{D} / \mathrm{D}_{0}\right)^{2}$ before and after the auto-ignition is obviously different in Fig. 6 (a). ARCs before and after the auto-ignition are defined as evaporation and burning rate constants respectively. Evaporation and burning rate constants are -0.139 and $2.466 \mathrm{~mm} / \mathrm{s}$ and their relative uncertainties are $12.41 \%$ and $3.24 \%$. Evaporation rate constant is negative because of the thermal expansion caused by droplet heating [46]. The evaporation rate constant is significantly lower than the burning one due to the flame heating. For BUT50, the method of polynomial fitting is not justified because of frequent bubble expansion and rupture in FE. The ARC in FE is calculated by Eq. (4) using a method of two-point fitting [47, 48],

$$
C_{F E}=-\frac{\left(D^{2} / D_{0}^{2}\right)_{\text {end }}-\left(D^{2} / D_{0}^{2}\right)_{s t a}}{\left(t / D_{0}^{2}\right)_{e n d}-\left(t / D_{0}^{2}\right)_{s t a}}
$$

where the subscripts sta and end are start and end points of FE. From Fig. 6 (b), $C_{F E}=1.69 \mathrm{~mm}^{2} / \mathrm{s}$ because $\left(D^{2} / D_{0}^{2}\right)_{s t a}=1.035$, $\left(t / D_{0}^{2}\right)_{\text {sta }}=0.050 \mathrm{~s} / \mathrm{mm}^{2},\left(D^{2} / D_{0}^{2}\right)_{\text {end }}=0.678$ and $\left(t / D_{0}{ }^{2}\right)_{\text {end }}=0.261 \mathrm{~s} / \mathrm{mm}^{2}$. The polynomial fitting can be used in TH and EE because the two phases are stable evaporation processes. However, the result of polynomial fitting in TH is poor because its duration is too short. ARCs in FE and EE are 1.404 and 2.148 and their relative uncertainties are $11.11 \%$ and $6.19 \%$. 


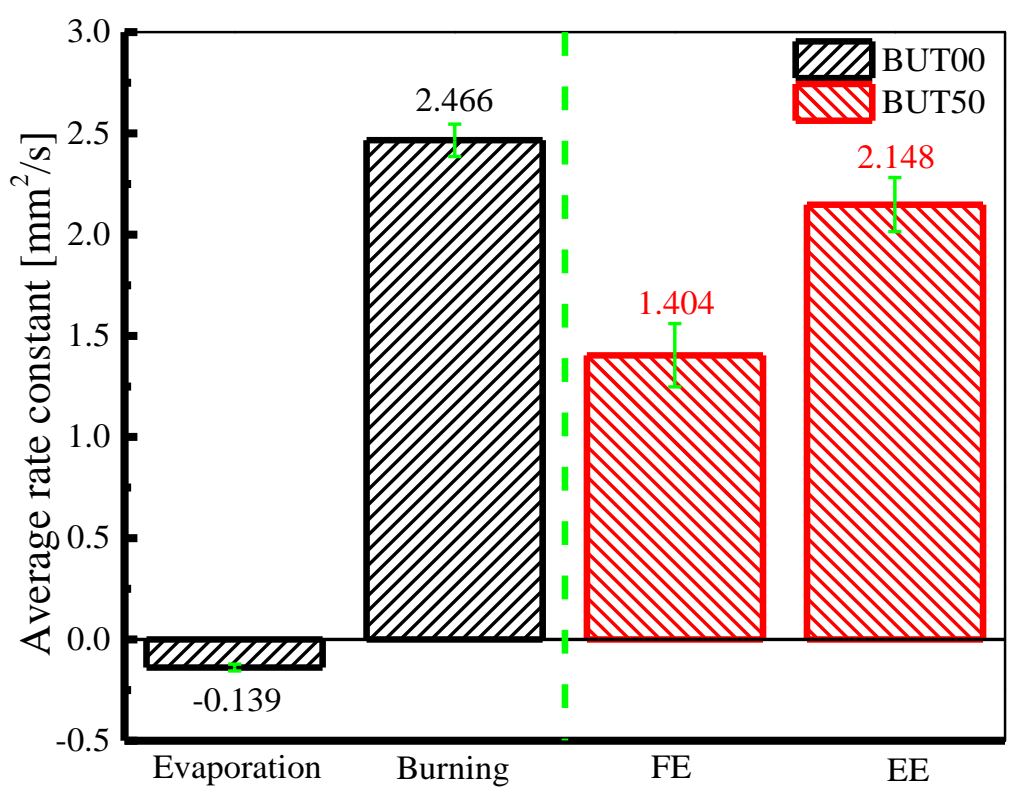

Fig. 8. Average rate constant (ARC) of BUT00 and BUT50.

Fig. 9 shows CT of BUT00 and BUT50. The droplet lifetime of BUT00 $\left(0.808 \mathrm{~s} / \mathrm{mm}^{2}\right)$ is longer than that of BUT50 (0.479 $\left.\mathrm{s} / \mathrm{mm}^{2}\right)$ due to two reasons. Firstly, the boiling point of n-butanol (390.4 K) is significantly lower than that of biodiesel (615 K).

This indicates the volatility of n-butanol is better than that of biodiesel. Secondly, BUT00 only demonstrates surface evaporation while BUT50 demonstrates surface and core evaporation. For BUT00 and BUT50, relative uncertainties of droplet lifetime are $2.04 \%$ and $5.89 \%$ respectively. From the perspective of cetane number, the auto-ignition delay of BUT00 is likely to be shorter than BUT50 because the cetane number of n-butanol (25) is less than that of biodiesel (51). However, the auto-ignition delay of BUT00 $\left(0.405 \mathrm{~s} / \mathrm{mm}^{2}\right)$ is longer than the two auto-ignition delays of BUT50 $\left(0.033\right.$ and $\left.0.218 \mathrm{~s} / \mathrm{mm}^{2}\right)$ in Fig. 9 . This can be explained by two reasons. Firstly, the droplet of BUT50 is enveloped by n-butanol vapor in the inception stage because of the high volatility of n-butanol. The first auto-ignition delay of BUT50 is shorter than BUT00 because n-butanol vapor can be ignited at $900 \mathrm{~K}$. Secondly, biodiesel vapor of BUT50 is more likely to ignite spontaneously than BUT00 because the combustion of n-butanol vapor leads to the increase of gas temperature and free radicals around the droplet. In this work, the reproducibility of experiments is analyzed through initial condition, PCP, ARC and CT. The reproducibility is quite good because relative uncertainties of these parameters are generally lower than $15 \%$. 


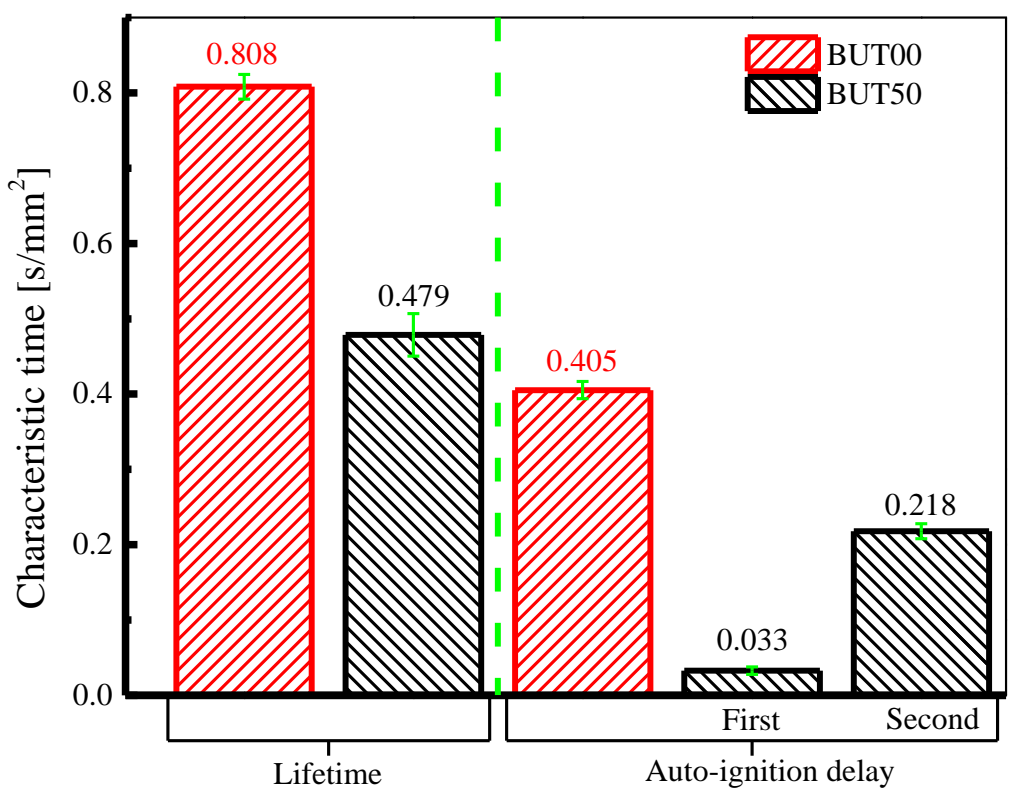

Fig. 9. Characteristic time (CT) of BUT00 and BUT50.

Fig. 10 shows droplet temperature and temperature growth rate (TGR) of BUT00 and BUT50. A temperature plateau can be found in the curve of temperature for BUT00 and BUT50, indicating that the droplet temperature has reached the wet temperature.

At the wet temperature, the energy for surface evaporation equals the heat transfer from ambient environment to droplet [36]. In

Fig. 10 (a), the TGR of BUT00 quickly decreases in the initial stage because violent droplet oscillation contributes to the heat exchange between ambient environment and droplet. The violent droplet oscillation is caused by the inertia effect of sudden stop when the droplet reaches the final location. Soon later, TGR becomes a slow and linear decrease before the auto-ignition. The difference between droplet and ambient temperatures gradually decreases with the increase of droplet temperature. The smaller temperature difference leads to the smaller rate of heat transfer from ambient environment to droplet. On the other hand, the evaporation rate gradually increases with the increase of droplet temperature. The higher evaporation rate leads to more energy for surface evaporation and less energy for droplet heating. After the auto-ignition, TGR sharply increases because of the flame heating. For BUT00, TGR is $1769 \mathrm{~K} \cdot \mathrm{mm}^{2} / \mathrm{s}$ at $0.609 \mathrm{~s} / \mathrm{mm}^{2}$ because the thermocouple junction is partially exposed to high temperature environment. From 0.609 to $0.770 \mathrm{~s} / \mathrm{mm}^{2}$, the temperature enters the temperature plateau and TGR is around 0 $\mathrm{K} \cdot \mathrm{mm}^{2} / \mathrm{s}$. After $0.770 \mathrm{~s} / \mathrm{mm}^{2}$, TGR increases drastically because the thermocouple junction is directly heated by ambient environment without the evaporation cooling [36]. 

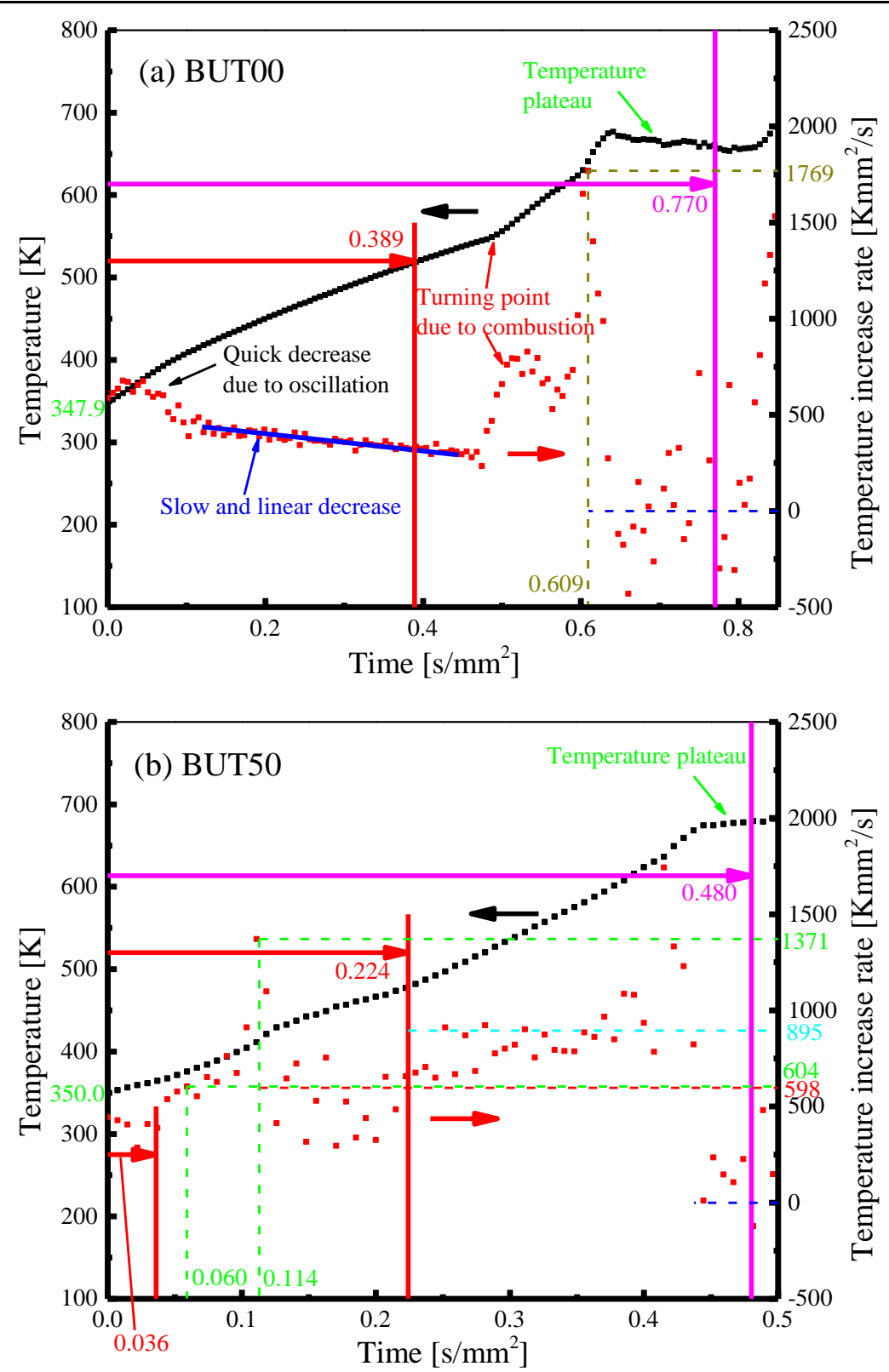

Fig. 10. Droplet temperature and temperature growth rate of BUT00 and BUT50.

In Fig. 10 (b), obvious fluctuation can be found in the curve of TGR for BUT50. The fluctuation is caused by the flame

heating and obvious droplet deformation. The droplet deformation leads to different thickness of fuel layer on the thermocouple

junction. Thicker fuel layer leads to lower TGR. TGR at $0.060 \mathrm{~s} / \mathrm{mm}^{2}\left(604 \mathrm{~K} \cdot \mathrm{mm}^{2} / \mathrm{s}\right)$ is significantly lower than that at 0.114

$\mathrm{s} / \mathrm{mm}^{2}\left(1371 \mathrm{~K} \cdot \mathrm{mm}^{2} / \mathrm{s}\right)$. At $0.060 \mathrm{~s} / \mathrm{mm}^{2}$, the thermocouple junction is surrounded by a large amount of fuel. At $0.114 \mathrm{~s} / \mathrm{mm}^{2}$, the

spindly droplet leads to the limited coverage of fuel on the thermocouple junction. From the first to the second auto-ignition, TGR

firstly increases and then decreases. This can be explained by two reasons. Firstly, the first flame undergoes flame development 
the heating of the second flame.

\section{Conclusions}

The droplet suspension technology was used to research the droplet combustion processes of BUT00 and BUT50 under 1 bar

and $900 \mathrm{~K}$. The major conclusions were summarized as follows.

(1) One flame is observed for BUT00 while two flames are observed for BUT50. The flame of BUT00 underwent

successively faint luminosity, bright luminosity, soot aggregate and soot spread. The first flame of BUT50 was faint and the

second one was similar to that of BUT00 because they were caused by n-butanol and biodiesel combustion respectively. The

addition of n-butanol contributed to the decrease of soot formation based on the change of flame characteristics.

(2) For BUT00, the flame led to the obvious change of $\left(\mathrm{D}_{/} \mathrm{D}_{0}\right)^{2}$, SD and TGR. Before the auto-ignition, $\left(\mathrm{D} / \mathrm{D}_{0}\right)^{2}$ was

approximately unchanged at 1.0 and SD was higher than 97\%. TGR decreased first quickly and then slowly. After the

auto-ignition, $\left(\mathrm{D} / \mathrm{D}_{0}\right)^{2}$ sharply decreased and SD was in the range of $90-97 \%$. The flame heating led to the increase of TGR and

spindly droplet shape. The SD of 90-97\% was caused by the continuous deformation of spindly droplet.

(3) For BUT50, obvious fluctuations were found in (D/D $\left.\mathrm{D}_{0}\right)^{2}$, SD and TGR. The SD of BUT50 was generally lower than $97 \%$.

The $\left(\mathrm{D} / \mathrm{D}_{0}\right)^{2}$ of BUT50 included TH, FE and EE phases. Although $\left(\mathrm{D} / \mathrm{D}_{0}\right)^{2}$ in FE was a non-deterministic process, some characteristic parameters were deterministic, including PCP, ARC and CT. Relative uncertainties of these parameters were generally lower than $15 \%$.

(4) The droplet lifetime of BUT00 was longer than that of BUT50. The auto-ignition delay of BUT00 was also longer than the two auto-ignition delays of BUT50. In a word, the flame heating and n-butanol addition enhanced evaporation and instability, which consequently improved the fuel-air mixing process.

\section{Acknowledgement}

This work was supported by the Graduate's Innovation Fund of Huazhong University of Science and Technology (No. 


\section{References:}

[1]. Huang Y, Organ B, Zhou JL, Surawski NC, Hong G, Chan EFC. Remote sensing of on-road vehicle emissions: mechanism, applications and a case study from Hong Kong. Atmos Environ 2018;182:58-74.

[2]. Huang Y, Ng ECY, Zhou JL, Surawski NC, Chan EFC, Hong G. Eco-driving technology for sustainable road transport: a review. Renew Sustain Energy Rev 2018;93:596-609.

[3]. Chang Y, Lee W, Lin S, Wang L. Green energy: water-containing acetone-butanol-ethanol diesel blends fueled in diesel engines. Appl Energy 2013;109:182-91.

[4]. Liu Y, Li J, Jin C. Fuel spray and combustion characteristics of butanol blends in a constant volume combustion chamber.

Energy Convers Manag 2015;105:1059-69.

blends on puffing characteristics. Fuel 2017;208:30-40.

2011;15:1098-116.

[8]. Liu H, Lee C, Huo M, Yao M. Comparison of ethanol and butanol as additives in soybean biodiesel using a constant volume combustion chamber. Energy Fuels 2011;25:1837-46.

[9]. Chang Y, Lee W, Wu TS, Wu C, Chen S. Use of water containing acetone-butanol-ethanol for $\mathrm{NO}_{\mathrm{x}}-\mathrm{PM}$ (nitrogen oxide-particulate matter) trade-off in the diesel engine fueled with biodiesel. Energy 2014;64:678-87.

[10]. Chauhan BS, Kumar N, Cho HM, Lim HC. A study on the performance and emission of a diesel engine fueled with Karanja biodiesel and its blends. Energy 2013;56:1-7.

[11]. Celik M, Yucesu HS, Guru M. Investigation of the effects of organic based manganese addition to biodiesel on combustion 
n-butanol and soybean biodiesel in a constant volume chamber under various ambient temperatures. Fuel 2014;133:317-25.

[13]. Jin C, Yao M, Liu H, Lee CF, Ji J. Progress in the production and application of n-butanol as a biofuel. Renew Sustain

Energy Rev 2011;15:4080-106.

[14]. Imdadul HK, Masjuki HH, Kalam MA, Zulkifli NWM, Alabdulkarem A, Rashed MM. Influences of ignition improver

[23]. Han K, Chen H, Yang B, Ma X, Song G, Li Y. Experimental investigation on droplet burning characteristics of diesel-benzyl 
azides blend. Fuel 2017;190:32-40.

342 [24]. Han K, Zhao C, Fu G, Zhang F, Pang S, Li Y. Evaporation characteristics of dual component droplet of benzyl

azides-hexadecane mixtures at elevated temperatures. Fuel 2015;157:270-78.

[25]. Han K, Song G, Ma X, Yang B. An experimental and theoretical study of the effect of suspended thermocouple on the single droplet evaporation. Appl Therm Eng 2016;101:568-75.

2016;166:59-66.

[27]. Han K, Yang B, Zhao C, Fu G, Ma X, Song G. Experimental study on evaporation characteristics of ethanol-diesel blend fuel droplet. Exp Therm Fluid Sci 2016;70:381-88.

[28]. Liu YC, Alam FE, Xu Y, Dryer FL, Avedisian CT, Farouk TI. Combustion characteristics of butanol isomers in multiphase droplet configurations. Combust Flame 2016;169:216-28.

[29]. Alam FE, Liu YC, Avedisian CT, Dryer FL, Farouk TI. n-Butanol droplet combustion: numerical modeling and reduced gravity experiments. Proc Combust Inst 2015;35:1693-700.

[30]. Li TX, Zhu DL, Akafuah NK, Saito K, Law CK. Synthesis, droplet combustion, and sooting characteristics of biodiesel produced from waste vegetable oils. Proc Combust Inst 2011;33:2039-46.

[31]. Marchese AJ, Vaughn TL, Kroenlein K, Dryer FL. Ignition delay of fatty acid methyl ester fuel droplets: microgravity experiments and detailed numerical modeling. Proc Combust Inst 2011;33:2021-30.

[32]. Das M, Chakraborty A, Datta A, Santra AK. Experimental studies on burning characteristics of methanol, diesel, and sunflower biodiesel fuels. Combust Sci Technol 2016;189:213-30.

[33]. Pan K, Chiu M. Droplet combustion of blended fuels with alcohol and biodiesel/diesel in microgravity condition. Fuel 2013;113:757-65.

[34]. Hoxie A, Schoo R, Braden J. Microexplosive combustion behavior of blended soybean oil and butanol droplets. Fuel 2014;120:22-29.

[35]. Coughlin B, Hoxie A. Combustion characteristics of ternary fuel blends: pentanol, butanol and vegetable oil. Fuel 
[36].Zhang Y, Huang R, Wang Z, Xu S, Huang S, Ma Y. Experimental study on puffing characteristics of biodiesel-butanol droplet. Fuel 2017;191:454-62.

[37]. Nomura H, Murakoshi T, Suganuma Y, Ujiie Y, Hashimoto N, Nishida H. Microgravity experiments of fuel droplet evaporation in sub- and supercritical environments. Proc Combust Inst 2017;36:2425-32.

[38]. Zhang Y, Huang R, Huang Y, Huang S, Ma Y, Xu S. Effect of ambient temperature on the puffing characteristics of single butanol-hexadecane droplet. Energy 2018;145:430-41.

[39]. Setyawan HY, Zhu M, Zhang Z, Zhang D. Ignition and combustion characteristics of single droplets of a crude glycerol in comparison with pure glycerol, petroleum diesel, biodiesel and ethanol. Energy 2016;113:153-59.

[40]. Khan QS, Baek SW, Ghassemi H. On the autoignition and combustion characteristics of kerosene droplets at elevated pressure and temperature. Combust Sci Technol 2007;179:2437-51.

[41]. Huang S, Deng P, Huang R, Wang Z, Ma Y, Dai H. Visualization research on spray atomization, evaporation and combustion processes of ethanol-diesel blend under LTC conditions. Energy Convers Manag 2015;106:911-20.

[42]. Hashimoto N, Nomura H, Suzuki M, Matsumoto T, Nishida H, Ozawa Y. Evaporation characteristics of a palm methyl ester droplet at high ambient temperatures. Fuel 2015;143:202-10.

[43]. Morin C, Chauveau C, Gokalp I. Droplet vaporisation characteristics of vegetable oil derived biofuels at high temperatures. Exp Therm Fluid Sci 2000;21:41-50.

[44]. Zhang Z, Balasubramanian R. Influence of butanol addition to diesel-biodiesel blend on engine performance and particulate emissions of a stationary diesel engine. Appl Energy 2014;119:530-36.

[45]. Rakopoulos DC, Rakopoulos CD, Hountalas DT, Kakaras EC, Giakoumis EG, Papagiannakis RG. Investigation of the performance and emissions of bus engine operating on butanol/diesel fuel blends. Fuel 2010;89:2781-90.

[46]. Ma X, Zhang F, Han K, Yang B, Song G. Evaporation characteristics of acetone-butanol-ethanol and diesel blends droplets at high ambient temperatures. Fuel 2015;160:43-49.

[47]. Lee SY, Baek SW. Experimental study on evaporation characteristics of ammonium formate-urea-water solution droplet for 
selective catalytic reduction applications. Ind Eng Chem Res 2011;50:8285-94.

390 [48]. Javed I, Baek SW, Waheed K. Effects of dense concentrations of aluminum nanoparticles on the evaporation behavior of

391 kerosene droplet at elevated temperatures: the phenomenon of microexplosion. Exp Therm Fluid Sci 2014;56:33-44. 